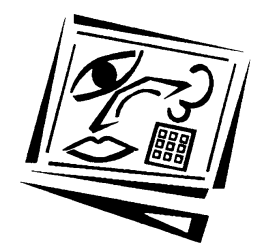

\title{
Modelling learner and educator interactions in an electronic learning community
}

\author{
Judy Sheard, Sita Ramakrishnan and Jan Miller \\ Monash University
}

\begin{abstract}
Critical to understanding how an electronic learning community can be established and sustained is understanding how learners and educators interact within the community. The study reported in this paper found that the development of an electronic learning community is a complex process that relies on the willingness of the learners to adopt a collaborative learning style. This appears to require a major shift in their learning behaviour and is a process in which the educators appear to have little influence. A discussion forum designed to provide a collaborative learning environment where students can discuss learning issues and provide feedback to staff has provided a vehicle for this study. An investigation of student and staff use of the discussion forum has informed the development of a set of visual representations that may be used to describe electronic learning communities.
\end{abstract}

\section{Introduction}

With the emergence of the Web and its rapid adoption for use in tertiary education, many students are now provided with electronic learning environments for part or all of their learning interactions. The widespread use of Web technology has encouraged a shift in pedagogical thinking by educators and has supported the move from teacher centred to learner centred education (Lefoe, 1998). As a consequence of these changes, many learner interactions are now happening in an electronic environment, often in isolation from the educators and other learners $(\mathrm{Ng}, 2001)$. With the changing focus away from face to face interactions, online learning interactions are assuming a new importance in the educational experiences of our students. Although the online learning environment provides advantages to students, releasing them from the constraints of time and place, it also deprives them of opportunities for the social and learning interactions afforded by face to face learning situations (Kreijns, Kirschner, \& Jochems, 2002). Social interactions are important to learning and the lack 
of these experiences has been used to explain low retention rates in online courses (Hill, 2001). In seeking ways to compensate for this, educators have encouraged online communication and collaboration between learners, fostering the development of online communities of learners (McKenzie \& Murphy, 2000; Ng, 2001).

The concept of an electronic learning community has evolved from a recognition of the need to support learners working in the isolation of an online environment. A community may be viewed as a form of relationship between individuals with shared goals and mutual needs. In an educational context this may be manifested by sharing of resources, ideas and perspectives and providing mutual assistance (McLoughlin \& Luca, 1999). In addition, it provides a social environment that can motivate and support students in their learning (Kreijns et al., 2002). In an online environment, a learning community is enabled and sustained by the use of communication facilities (McKenzie \& Murphy, 2000). In recent years there has been an increasing use of various forms of online communication facilities which have encouraged the formation of electronic learning communities; however, there are concerns that the use of these facilities for the purpose of establishing learning communities is not founded on theories which can guide their effective and appropriate use (Gunawardena, Lowe, \& Anderson, 1997).

A facility to enable and foster the establishment of course based electronic learning communities was developed by staff within the School of Computer Science and Software Engineering (CSSE) at Monash University. The facility in the form of an anonymous feedback and discussion forum was introduced in 1997 and since that time has been incorporated in a range of courses within the School. An investigation into the use of this facility from the student and staff perspectives has provided insights into the use and management of electronic discussion forums to encourage learning communities. The data have provided the basis for the development of a set of diagrams that can be used to describe the electronic learning community interactions and assist in the understanding of the mechanisms that encourage and sustain electronic learning communities.

\section{Electronic learning communities}

An electronic learning community is founded on the concept of a group of learners communicating and collaborating online in a mutually beneficial way. The basis for understanding the advantages of these communities to the learner can be found in the constructivist approach to education, which emphasises the active participation of the learner in the learning process. The constructivist view is that learning is an evolving and active 
process, and the role of the teacher in this process is as a facilitator (Owen, 2000). A constructivist learning environment provides learners with opportunities to engage in learning activities which are intentional and contextualised, offering them opportunities for reflection and communication with other learners (Jonassen \& Rohrer-Murphy, 1999). These environments may be seen to encourage collaboration between learners, emphasising the importance of social interactions in learning (Ewing \& Miller, 2002; McLoughlin \& Luca, 1999). An electronic learning community in this context provides the learner with opportunities to engage online in learning activities in a socially constructive way.

Essential to the establishment of an electronic learning community is the facilitation of online communication between potential community members. This may be enabled via synchronous or asynchronous means. Synchronous communication requires participants to be present at the same time; asynchronous communication does not require the participants to be present at the same time, allowing them the opportunity to reflect upon and consider their responses (Liaw \& Huang, 2000). Comparing the two forms of communication, Hegngi (1998) found that synchronous discussion encouraged more participation, whereas asynchronous discussions generated more student initiated discussion topics and a greater number of ideas.

According to the constructivist view, knowledge is constructed by the learner and part of that process is interacting and sharing knowledge with other learners. Jonassen, Peck and Wilson (1999) state that learning most naturally occurs by "teams of people working together to solve problems" (p. 200). In this context participation in an electronic learning community should be beneficial to the students' learning, providing a place where they can contribute ideas and discuss problems, carefully monitored and supported by teaching staff. However, McLoughlin and Luca (1999) warn that they may provide only limited learning opportunities. In their analysis of online discussion forum contributions they found that, although there was a sharing of ideas, the learners did not tend to engage in critical analysis of other participants' ideas. Other studies present more positive perspectives. A study of the use of an online discussion forum by $\mathrm{Ng}$ (2001) found that, "learners treasured the opportunity to share information and thoughts" (p.531) and this facility fostered self directed and collaborative learning. Another study by McKenzie and Murphy (2000) showed that an online discussion group had been an effective part of a learning environment.

Critical to the success of discussion forums is active student participation. Goodwin, Graham, and Scarborough (2001) claim that not all students accept the collaborative learning model, with some preferring to work on 
their own. In agreement, Oliver (2002) found that many students are disinclined to participate in online discussions, preferring to passively browse and read rather than actively contribute postings. Barnes (1997) offerred students anonymity in a discussion forum to encourage a wide body of students to participate in analysis and criticism. He thus acknowledges their right to ask questions without fear of consequences. However, Nalohy and Munns (2000) maintain that anonymity can encourage negative or irresponsible use. In online discussion forums all levels of participation, from communicative to non-communicative, are possible, however the sustaining of a community relies upon active participation (Hammond, 1999).

The establishment of an electronic learning community is contingent upon the educator providing appropriate communication facilities. In addition to this, many are in agreement that the educator has a further role in developing and sustaining the learning community. However, there are various opinions on the type of role that the educator should adopt. Some argue that educators should be pro-active in directing and controlling their online communities and that this is important for facilitating participation (Ho, 2002). McLoughlin and Luca (1999) contend that educators have an essential role in ensuring that the processes and activities in online forums "are conducive to learning while supporting collaboration" (p.218). Taking a similar view, Owen (2000) advocates that in online forums, "good moderation and structure are needed to sustain good learning". Adding support to this, Lowder and Hagan (1999) claim that staff should partake in online discussion to help the online community find direction. However, they also maintain that staff should be available to solve problems. In this more reactive role the educator may be seen as providing an online helpdesk.

From another perspective, students also have views and expectations about the role of the educator in online communities. $\mathrm{Ng}$ (2001) found that students expected the educator to play a supporting rather than an authoritative role. Mazzolini and Maddison (2003) report that students reacted favourably to the perceived enthusiasm and expertise of teachers who posted frequently to discussion, however this did not result in greater student participation. They also found that students reacted more positively to questions posted by fellow students rather than questions posed by instructors. The difficulty with the management of electronic learning communities seems to be with finding an appropriate balance. As Nanlohy and Munns (2000) argue,

If users feel too restricted by the limitations that have been placed on the discussion board they are less likely to use it fully. If no guidelines are placed on the board it is possible that the use of the discussion space will be purposeless. 
In summary, the literature suggests that electronic learning communities can provide opportunities for social and collaborative learning experiences in the isolating online environment. There are a variety of ways reported about how electronic learning communities are used and managed and it seems that the establishment and sustaining of these communities can be difficult. Critical to understanding electronic learning communities is the interrelationship between students and educators in these communities. However, the research on electronic learning communities has generally focused on student issues and there is a scarcity of studies from the educator perspective. Furthermore, there is little attempt to systemise these findings from a pedagogical point of view. In this paper we present a set of diagrams that can be used to describe the electronic learning community interactions. The visual representations were developed from results of two separate studies of students and teaching staff within the School of Computer Science and Software Engineering at Monash University. The diagrams describe the levels of student and staff engagement in an electronic learning community and the degree of proactivity or reactivity of their interactions. It is essential for educators to understand the ways in which these communities function, to ensure the provision of learning environments which will support learners working in the remote and isolating online environment.

\section{Context of the research}

A Web based discussion forum used widely in the School of Computer Science and Software Engineering (CSSE) was developed by staff in 1997. The facility known as Anonymous Feedback or Discussion Forum was originally intended to provide a cooperative learning environment where students could discuss learning issues and provide feedback to staff; however, it has evolved an additional purpose as an online help desk. Since its introduction it has been enhanced and refined with the current version now providing for:

- Linear and threaded asynchronous discussion;

- Optional anonymity of postings;

- Email notification of postings for teaching staff;

- Moderation of postings by staff;

- Filtering of offensive language;

- Administrative facility allowing for customisation of interface;

- Statistics of usage.

\section{Study methods}

This study draws upon data that was collected in 2001 and 2002 via separate surveys of students and teaching staff in the School of Computer 
Science and Software Engineering (CSSE) at Monash University. Survey questionnaires were developed by members of the Monash University Computing Education Research Group (CERG) who were also teaching staff within CSSE.

The students' questionnaire contained questions to determine students' demographic information, their use of the Anonymous Feedback facility, and their opinions of its usability, usefulness as a source of assistance and effectiveness as a mechanism to provide feedback to staff. Students from eight units were invited to participate in the study. The units were selected from each year level of undergraduate courses and two graduate courses within the School of Computer Science and Software Engineering (CSSE). A total of 436 students responded to the surveys.

The teaching staff questionnaire contained questions to gather information about staff use and management of discussion forums, and their perceptions of their usefulness as a source of assistance and effectiveness as a feedback mechanism. Lecturers of CSSE undergraduate and graduate programs were invited to participate in the survey.

\section{Results}

The results of the surveys revealed a pattern of behaviour among staff and students with respect to their use of discussion forums and engagement in online collaborative work practices. In this section, we present a summary of the findings from these surveys. We then present mini case studies of the teaching staff whose units were surveyed in the student survey. Based on the findings, we provide a visual representation and explanation of the development of electronic learning communities.

\section{Student and staff surveys}

The student survey showed that a discussion forum is a popular and valued resource for students. A high percentage of students in this study (79\%) used the Anonymous Feedback discussion forum during the semester of the survey. More than half the students $(67 \%)$ claimed they had made postings during the semester. The frequency of postings varied widely over the units in the study, from a mean of 2.1 to 9.4 postings per student. Of particular interest in this study was the type of usage students were making of Anonymous Feedback. The most common reason for making a posting was to seek help with assignment work, with half the students having posted requests for this type of assistance. Far fewer students $(18 \%)$ made postings to give feedback to teaching staff or make reflective comments on other aspects of their work. Further details of this study have been reported elsewhere (Sheard, Miller, Ramakrishnan \& Hurst, 2002). 
Thirty-one lecturers responded to the staff survey, with 15 of these using a discussion forum in their course. Discussion forums were used at all levels of undergraduate and postgraduate teaching with a trend to more frequent use in courses at the first and second year undergraduate levels. Twelve of the respondents who used a discussion forum in their course used the CERG Anonymous Feedback facility. Most lecturers had taken full or most of the responsibility for the operation of the discussion forum in their course with minimal assistance from tutorial staff. Further details of this study have been reported elsewhere (Sheard, Miller, \& Ramakrishnan, 2003).

\section{Case studies: An overview}

Analysis of the survey results revealed that the lecturers in this study used different approaches in the provision of discussion forums and there were a variety of responses and degrees of participation from the students. To gain further insights into the use and management of this facility, mini case studies of seven of the teaching staff from the units surveyed in the student survey are presented. These give a snapshot of staff views of the use of discussion forums at each year level of the undergraduate and graduate courses. The undergraduate units were programming or software engineering courses and had class sizes of over 200 students; the postgraduate unit was a programming course and had a class size of over 100 students. All lecturers used the Anonymous Feedback facility, which will be referred to as a discussion forum in these case studies.

\section{Case studies First year level}

The students in both first year units in this study demonstrated a willingness to use discussion forums; however, most of their participation was passive or in the form of requests for assistance with assignment work or exam preparation. Very few students responded to postings from other students. The lecturers claimed their discussion forums were an important point of contact for first year students who found it reassuring and helpful to have this facility. Both lecturers were actively involved in their discussion forums and had assistance from two or three other tutors who were less active. However, their management of their forums was quite different and suggests that these forums were largely student driven.

One lecturer spent approximately 12-16 hours per week responding to postings and accessed the discussion forum every day. She found the facility difficult to manage and claimed that she was under constant pressure to answer postings from students whom she contended had unreasonable expectations of assistance and response times. She had been annoyed and upset by some postings and felt that anonymity of postings 
had encouraged whinging from students. However, it is interesting that she pro-actively encouraged students to use the forum by posting messages to promote discussion.

Presenting quite a different perspective, the other lecturer spent approximately 1 hour per week responding to postings and accessed the discussion forum only twice weekly. She was reactive in her use of the forum, only posting to respond to students' questions or comments. She found the facility easy to manage and never felt under any pressure. She argued that anonymity of postings was an important feature and, although she had sometimes been irritated by postings, she had never been upset. This difference in style could, in part, be explained by her greater teaching experience and the fact that she had been using the facility since its introduction in 1997.

\section{Case studies Second year level}

The enthusiastic use of discussion forums can become a burden on the teaching staff. The two second year units in this study illustrated this. The students in both units were more active in their discussion forums than the first year students and the activity started earlier in the semester. As was found with the first year students, most of the postings were requests for assistance with assignment work, with high volumes of postings just before assignment submissions and the final exam.

Both lecturers found their discussion forums difficult to manage. They accessed their forums every day and spent from 5 to 6 hours each week responding to postings. They felt the postings were responded to in a reasonable time, however they were almost constantly under pressure with what they perceived as the students having unreasonable expectations of response time and the type of assistance they should be given. The lecturers were actively involved in their discussion forums and had assistance from one or two other tutors who were less active. They encouraged their students to use their forums; however they were reactive in their own use, only posting in response to other postings.

The lecturers were not in agreement about the value of their discussion forums as feedback mechanisms to staff; however they maintained that they were very useful sources of help for students. Both lecturers claimed their forums were being used by students as online helpdesks and required a lot of effort to maintain. They wanted their tutors to share in this work but felt it was unfair to expect them to do this without payment.

A further problem was experienced with these discussion forums. Both lecturers had been irritated and occasionally upset by critical or offensive 
postings. The lecturers argued that it was not desirable to allow students to make comments anonymously as this had resulted in irresponsible use of the forum. They claimed that students should be encouraged to take ownership of their statements.

\section{Case studies Third year level}

Collaborative learning in online discussion forums relies on active engagement between learners. In this study this type of behaviour was only exhibited, to any large degree, in the two third year units, where students responded to other students' postings in addition to posting questions or comments. The third year students were the most active of all students surveyed, with more than three times the volume of postings compared with units at other year levels. Also showing a different pattern of use, these students used their discussion forums constantly throughout the semester with peaks in numbers of postings around assignment submissions and exam time. Furthermore they exhibited more responsibility in their use of the forums. Many students in these units tended to identify themselves in their postings and the lecturers claimed there were very few problems with offensive postings.

Both lecturers managed their discussion forums with assistance from one or two tutors. They found their forums easy to manage and claimed their students were not unreasonable in their expectations. They maintained that online discussion forums facilitate access to large groups of students more easily than is possible with face to face help desks. The lecturers showed quite different levels of engagement with their discussion forums, which supported the indications from the first year units that these forums were largely student driven.

One lecturer accessed his discussion forum twice a week and spent from 34 hours per week responding to postings. He was not pro-active in his use of the forum and did not strongly encourage his students to use it. However he claimed that the forum was an easy and more efficient way of providing feedback and promoting discussions among students in the unit.

In contrast, the other lecturer accessed his discussion forum every day and spent about 10 hours per week making or responding to postings. He strongly encouraged his students to use the forum and was very proactive in his own use, frequently posting informational and explanatory messages. He also encouraged tutors to participate and some did to a limited degree. He claimed the forum was a very useful source of help for students and also useful for him to gain feedback. For this lecturer the discussion forum was an integral part of his teaching strategy. 


\section{Case study Graduate level}

Students in graduate courses typically take more responsibility for their learning and it might be expected that they would be willing to engage in collaborative learning. It was therefore interesting that in this study the lecturer of the graduate level unit reported experiences about her discussion forum that, to a degree, were similar to those of the first year lecturing staff.

The graduate students showed the same level and type of activity in their discussion forum as the first year students. Similarly, most of the postings were requests for assistance and postings were very heavy just before assignment submissions and the final exam. In this unit there were some problems with students posting offensive messages and the lecturer was concerned about their impact on the morale of other students and tutors. She claimed that some students were demanding, with unreasonable expectations of response time and requests for assistance. She encouraged students to sign posting in order to take ownership of their work, however very few did this.

The lecturer in this unit claimed that the discussion forum was a great source of help for the students, but less useful as a feedback mechanism to staff. Her role in the discussion forum was only reactive. She found that the online discussion forum required a lot of extra effort and contended that it took 10 times the effort as compared to a face to face help desk facility. The lecturer answered all the administration questions and shared the responses to the requests for help with a tutor who was very active. The lecturer felt that tutors should assist more; however, with the way the system was set up, requests for assistance were broadcast to the lecturer and all tutors, and it required some effort to check if a posting had been answered. This led to difficulty in the management of shared responsibility.

\section{Modelling the electronic learning community}

From the mini case studies presented, and drawing on findings from the student and staff surveys, a set of visual representations of learner and educator interactions with discussion forums has been developed. These are shown in Figure 1. The diagrams present four variations on possible combinations of learner and educator interactions. The solid ended arrows are used to indicate the learners and the open ended arrows are used to indicate the educators. The educators may be lecturers (shown with a solid line) or tutors (shown with a dashed line). The numbers of arrows indicate the relative volume of postings. 
1. Virtual help desk: educator reactive

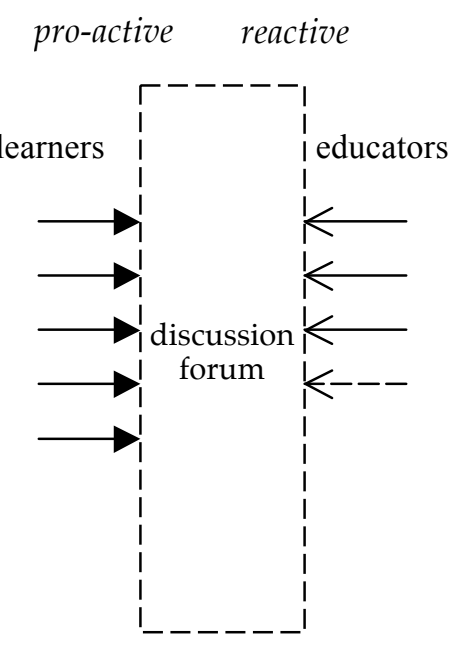

\section{Electronic learning} community: educator reactive

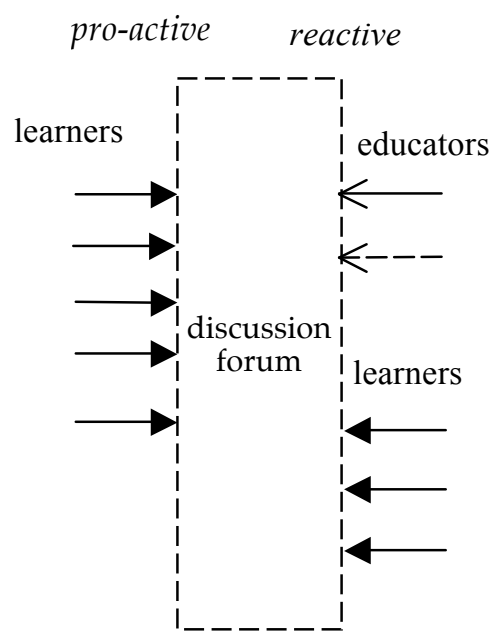

2. Virtual help desk: educator pro-active

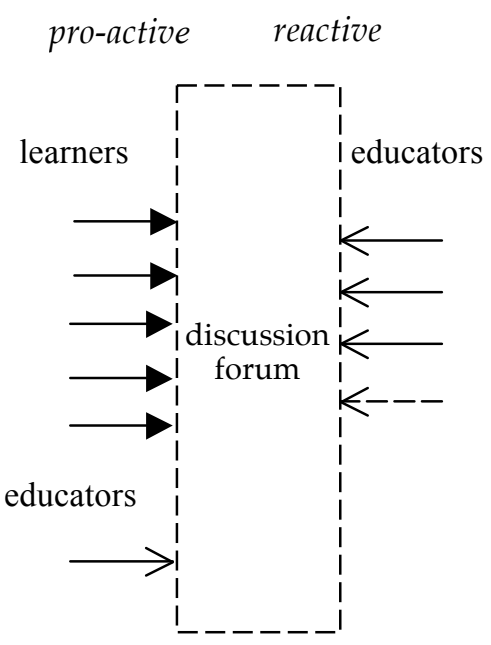

4. Electronic learning community: educator pro-active

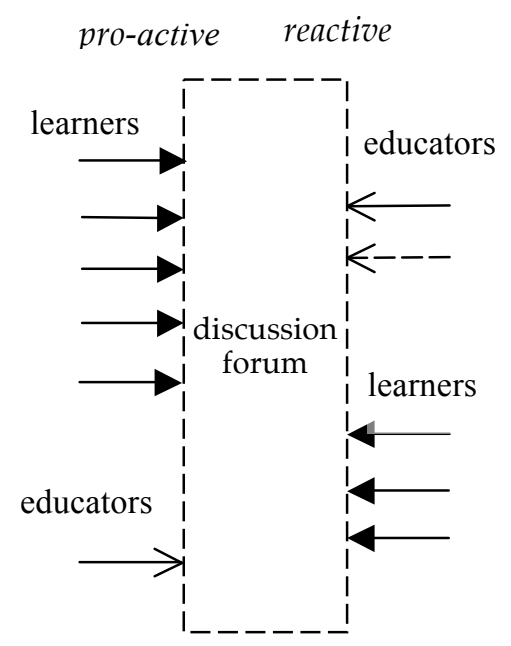

Figure 1: Models of learner and educator interactions 
The interactions may be further explained by whether they are pro-active, for example, posting a question or informational message, or reactive, for example, responding to a posted question. Pro-active interactions are shown on the left and reactive interactions are shown on the right.

Diagrams 1 and 2 show the learners as pro-active and the educators as reactive in their use of their discussion forums, with Diagram 2 also showing the educators as exhibiting a small degree of pro-activity. These two diagrams illustrate the behaviour of students and lecturers in the first year level and graduate level units in our study. In these units most interactions were student initiated, with the lecturer participating on request or, as some lecturers claimed, on demand. Most student interactions were requests or comments to the teaching staff rather than reflection or engagement with other students. Such patterns of interactions do not describe collaborative learning and these discussion forums could not be considered electronic learning communities; alternatively, they are better described as online help desks. It is important to note here that the degree of pro-activity of the lecturers did not affect the behaviour of the students. The behaviour of the second year level students showed some engagement beyond questions or comments directed to the teaching staff, with some learner to learner interactions; however, their use of their discussion forums still resembled a virtual help desk rather than an online learning community.

Diagrams 3 and 4 describe the behaviour of students in the third year level units in our study. Here the students were engaged both pro-actively and reactively, posting comments and questions and responding to postings from other learners. Aligned with this there was an observed trend to more responsible use of the forum with fewer inappropriate or offensive postings. The students here were engaged in collaborative learning, forming what can be termed an electronic learning community. However, it is interesting to note that, as with the first year units, the degree of proactivity of the lecturers did not affect the behaviour of the students.

\section{Establishing an electronic learning community}

Student behaviour is not always exhibited in the ways we expect. As educators we can provide a learning environment for our students, and encourage and guide their learning; however, beyond this we have little control over their learning behaviour. The educators in this study provided a discussion forum that was intended as a facility to enable the development of a cooperative learning environment, however it was not used in this way in all units. 
We observe from our study that electronic learning communities were only established successfully in the highest year levels of the undergraduate course. This indicates a change in learning behaviour of the students as they progress through their course. A possible explanation for this could be that with maturity students take more responsibility for their learning and adopt a self directed approach to learning. However, we must look to other explanations to explain the reluctance of the graduate level students to engage in collaborative learning. Another possible explanation is that students in the first year level and graduate units have often come from traditional teacher centred environments and have not experienced an online learning environment. Their model of learning is focused on the learner-educator interactions, which they emulate in the online environment. It appears that the establishment of electronic learning communities requires a shift in learner behaviour. This takes time to develop and it cannot be assumed that if provided with an online discussion forum that students will adopt this behaviour readily.

Examining this from a constructivist perspective, according to Jonassen, Peck and Wilson (1999) an important component of constructivist learning is engagement in collaborative discussions as a means of assisting knowledge building and reflection on learning. The role of the educators here is to set the rules for discussion forums, to facilitate the engagement process. Discussions should then continue between the students who explore, reflect and elaborate on their ideas to find collaborative solutions. In our study the lecturers exhibited a variety of techniques for managing their discussion forums; however, we found that the pro-activity and level of engagement of the lecturers in this process had no apparent effect. The establishment and sustaining of the electronic learning communities was a student driven process.

The concept of a learning community implies ownership and sharing of ideas in an open forum with participants making themselves known to others. Learners cannot really collaborate and build relationships of trust if they hide behind anonymity. Therefore, allowing and encouraging anonymity may be seen to inhibit the development of electronic learning communities. Anonymous forums may be appropriate for the novice learner to enable them to engage with the lecturer without fear; however, as they gain maturity, the instructional strategy and content should be changed to accommodate the level of the learners. This is in line with Ertmer and Newby (1993) who advocate matching learning strategies with the content to be learned and the maturity of the learners. In our study, anonymity was optional and was used by fewer students in the higher year level units. It seems that by the third year of their course the students had gained an understanding of the collaborative learning model and 
were willing to participate openly in a public forum, enabling the development of successful electronic learning communities.

\section{Conclusion}

The diagrams developed from the mini case studies and surveys help illustrate the complexity of learner and teacher interactions within online discussion forums. It is clear that not all these can be seen as modelling electronic learning communities. In our study, electronic learning communities were only successfully established in the third year of our undergraduate course. We found that the development of online learning communities is largely driven by the learners, with the educators having very little influence in this process. Further investigation is required to determine specific strategies, appropriate for each year level, which educators can use to encourage a shift in student behaviour towards actively and effectively participating in an electronic learning community. Acknowledging the benefits of the constructivist approach, we conclude that educators need to consider the tailoring of learning support environments according to the maturity of the learner and also the kinds of interactions we wish to support in these environments.

\section{References}

Barnes, D. (1997). Students asking questions: Facilitating questioning aids understanding and enhances software engineering skills. SIGCSE Bulletin inroads, 29(4), 38-41.

Ertmer, P. A., \& Newby, T. A. (1993). Behaviorism, cognition, constructivism: Comparing critical features from an instructional design perspective. Performance Improvement Quarterly, 6(40), 50-72.

Ewing, J. \& Miller, D. (2002). A framework for evaluating computer supported collaborative learning. Educational Technology E Society, 5(1), 112-118. http:/ / ifets.ieee.org/periodical/vol_1_2002/ewing.html

Goodwin, C., Graham, M., \& Scarborough, H. (2001). Developing an asynchronous learning network. Educational and Technology \& Society, 4(4), 39-47. http: / /ifets.ieee.org/periodical/vol_4_2001/scarborough.html

Gunawardena, C. N., Lowe, C. A. \& Anderson, T. (1997). Analysis of a global online debate and the development of an interaction analysis model for examining the social construction of knowledge in computer conferencing. Journal of Educational Computing Research, 17(4), 397-431. 
Hammond, M. (1999). Issues associated with participation in on line forums - the case of the communicative learner. Education and Information Technologies, 4(4), 353-367.

Hegngi, Y. N. (1998). Changing roles, changing technologies: The design, development, implementation, and evaluation of a media technology and diversity on-line course. Proceedings of the Annual meeting of the American Educational Research Association, San Diego, CA, 1-30.

Hill, J. R. (2001). Building community in Web-based learning environments: Strategies and techniques. Proceedings of the Seventh Australian World Wide Web Conference (AusWeb 2001), NSW, Australia.

http: / / ausweb.scu.edu.au/aw01/ papers/ refereed/hill/ paper.html

Ho, S. (2002). Encouraging online participation? Proceedings of the 11th Annual Teaching and Learning Forum 2002, Perth, Australia. http: / / www.ecu.edu.au/ conferences/tlf/2002/pub/docs/Ho.pdf

Jonassen, D. H., Peck, K. L., \& Wilson, B. G. (1999). Learning with Technology: A Constructivist Perspective. Upper Saddle River, NJ 07458: Prentice Hall, Inc.

Jonassen, D. H., \& Rohrer-Murphy, L. (1999). Activity theory as a framework for designing constructivist learning environments. Educational Technology Research $\mathcal{E}$ Development, 47(1), 61-79.

Kreijns, K., Kirschner, P. A., \& Jochems, W. (2002). The sociability of computer suppoted collaborative learning environments. Educational Technology \& Society, 5(1). http:/ / ifets.ieee.org/periodical/vol_1_2002/kreijns.html

Lefoe, G. (1998). Creating constructivist learning environments on the Web: The challenge in higher education. Proceedings of the 15th Annual Conference of the Australasian Society for Computers in Learning in Tertiary Education (ASCILITE'98), Wollongong, NSW.

http: / / www.ascilite.org.au / conferences / wollongong98/asc98pdf/lefoe00162.pdf

Liaw, S.-S. \& Huang, H.-M. (2000). Enhancing interactivity in Web-based instruction: A review of the literature. Educational Technology, 40(3), 41-45.

Lowder, J., \& Hagan, D. (1999). Web-based student feedback to improve learning. Proceedings of the Innovation and Technology in Computer Science Education (ITiCSE'99), Cracow, Poland, 151-154.

Mazzolini, M., \& Maddison, S. (2003). Sage, guide or ghost? The effect of instructor intervention on student participation in online discussion forums. Computers $\mathcal{E}$ Education, 40, 237-253.

McKenzie, W., \& Murphy, D. (2000). "I hope this goes somewhere": Evaluation of an online discussion group. Australian Journal of Educational Technology, 16(3), 239-257. http:/ / www.ascilite.org.au/ajet/ajet16/mckenzie.html 
McLoughlin, C., \& Luca, J. (1999). Lonely outpourings or reasoned dialogue? An analysis of text-based conferencing as a tool to support learning. Proceedings of the 16th Annual Conference of the Australasian Society for Computers in Learning in Tertiary Education (ASCILITE '99), Brisbane, Australia, 217-228.

http:/ / www.ascilite.org.au/conferences/brisbane99/papers/mcloughlinluca.pdf

Nanlohy, P., \& Munns, G. (2000). A virtual tutorial - engagement and encounter in an on-line learning community. Proceedings of the Australian Association for Research in Education Annual Conference, Sydney, Australia. http:/ / www.aare.edu.au/00pap/nan00111.htm

$\mathrm{Ng}$, E. M. W. (2001). Fostered self-directed and collaborative learning using electronic discussion forum. Proceedings of the 9th International Conference on Computers in Education/SchoolNet 2001, Seoul, Korea, 531-534.

Oliver, R. (2002). Should we make participation in discussion and bulletin boards in online learners settings compulsory? Proceedings of the 11th Annual Teaching and Learning Forum 2002, Perth, Australia.

http: / / lsn.curtin.edu.au/tlf/tlf2002/abstracts / oliverr-abs.html

Owen, M. (2000). Structure and discourse in a telematic learning environment. Educational Technology \& Society, 3(3).

http:/ / ifets.ieee.org/periodical/vol_3_2000/b04.html

Sheard, J., Miller, J., \& Ramakrishnan, S. (2003). Web-based discussion forums: The staff perspective. Proceedings of the 8th Annual Conference on Innovation and Technology in Computer Science Education (ITiCSE 2003), Thessaloniki, Greece. 158-162.

Sheard, J., Miller, J., Ramakrishnan, S., \& Hurst, J. (2002). Student satisfaction with a Web-based anonymous feedback system. Proceedings of the Eighth Australian World Wide Web Conference (AUSWEB 2002), 405-415.

http: / / ausweb.scu.edu.au/aw02/ papers/ refereed/sheard3 / paper.html

Judy Sheard, Sita Ramakrishnan and Jan Miller School of Computer Science and Software Engineering Monash University, Australia 